\title{
Mental Illness in Primary Care Settings
}

\author{
Greg Wilkinson, Honorary Lecturer, General Practice Research Unit, Institute of Psychiatry, London
}

A Conference on the above topic took place at the Institute of Psychiatry, London, on 17 and 18 July 1984. The Conference was sponsored by the Department of Health and Social Security and was organized by the General Practice Research Unit. Over 100 invited clinicians, research workers and policy-makers took part. The majority of the participants were either psychiatrists or general practitioners, but representatives of all relevant disciplines attended.

Dr E. D. Acheson, Chief Medical Officer at the DHSS, gave the opening address, in which he outlined the objectives of the conference. These were to promote exchanges between researchers and policy-makers, to review research in this field, and to help develop a future research strategy that would assist policy decisions. The Conference appeared to be relevant to a number of policy issues being considered by the Department: first, to give mental health greater priority as an integral part of health and social provision; secondly, to emphasize prevention; and thirdly, to provide for better co-operation among primary care teams, specialist services, and voluntary organizations.

Professor A. W. Clare and Dr D. L. Crombie began the proceedings with a discussion of the classification of mental disorders in general practice. The former concluded (from a review of work on affective disorder) that present classification models were inadequate for both clinical and research work in primary care, mainly due to the fact that current systems had been developed on patients already under the care of psychiatrists. He called for multi-axial systems of classification which allowed better specification of mild degrees of affective disturbance and mixed affective disorders, and the specification of psychological symptoms in the context of physical illness. The latter, Director of the Birmingham Research Unit of the Royal College of General Practitioners, concentrated on problems relevant to classification systems in general. The classification systems devised for the National Morbidity Surveys and for use with micro-computers in general practice would have to suffice until more reliable and valid methods of collecting clinical information became available.

On the subject of screening for psychiatric disorder in general practice. Dr Paul Williams drew a distinction between screening and case-finding. Case-finding was defined by Sackett and Holland as 'a process whereby patients who have sought health care are tested, with their consent, for disorders which may be unrelated to their present complaint'. Dr Williams argued, using the Wilson and Junger criteria for the assessment of screening, that screening for psychiatric disorder was not yet ready for inclusion in the health services, but that there was 'probably sufficient evidence to indicate that case-finding for psychiatric disorder should be recommended for adop- tion as health care policy'. Dr John Fry also argued against screening for mental illness in general practice. His case was based on the deficits in current knowledge regarding the aetiology and natural history of mental disorders, the absence of a reliable classificatory system, and the absence of agreed tests for making uniformed diagnoses. He had found that none of the current screening methods were of practical assistance to the work of the general practitioner.

Professor Margot Jefferys said that the importance of the family, non-medical agencies and self-help groups, in caring for the mentally ill should not be overlooked. She discussed some of the major problems involved in professional collaboration: in particular, the social status disparities involving the objection of health visitors, social workers and nurses to being placed in a subordinate role to general practitioners. Dr John Horder continued with this theme and concentrated on the work of the primary care team, giving as an example a case-study of a family with multiple social and health problems with which he had been involved. He described some of the advantages of team work, the tasks which could be carried out, and the involvement of visiting psychiatrists and psychotherapists in this work. While Professor Jefferys questioned whether precise job descriptions were the solution to interoccupational rivalry, Dr Horder concluded that the roles of team members must overlap as, in his view, the personality and aptitude of any team member were as important in mental health work as was professional training.

The effectiveness of treatment for mental disorders in general practice was dealt with by Professor G. W. Ashcroft and Dr A. Ryle. Professor Ashcroft presented his recent work on the drug treatment of depressive and panic attack syndromes in Aberdeenshire. He illustrated some of the issues raised by work in this field, and described some 'puzzling or anomalous findings' arising from his experiences, over seven years, of drug trials in general practice settings: for example, differences between self and observer ratings, the relationship between compliance and effectiveness, the failure of symptom profiles to be predictive of outcome, a possible new side-effect syndrome, a delayed placebo effect, and the dramatic response of panic attack to brief antidepressant therapy. Dr Ryle, in contrast, presented a literature review, and suggested that thorough research of mental health interventions by health care professionals in primary care was called for.

Dr Geraldine Strathdee captured attention when she gave the results of a survey which she had conducted to determine the extent and nature of the work undertaken by psychiatrists in England and Wales in the general practice setting. The survey showed that since the 1960s there has been a steadily growing number of psychiatrists (about 1in-5 of those surveyed) who are participating in liaisonattachment schemes with general practitioners. The nation- 
wide development of these schemes could be seen as the result of diverse factors: the move within psychiatry towards community care; the growth in the number of health centres; the development of general practitioner vocational training schemes. Moreover, in spite of the uncoordinated nature of the development of this pattern of service, three clearly distinguishable patterns of working collaboration could be identified: a consultation pattern; a shifted out-patient pattern; and a liaison-attachment team pattern. In general, psychiatrists seemed to be enthusiastic about the benefits to be derived from this type of service, both in terms of clinical care for patients and in opportunities provided for education and collaboration with general practitioners.

Speakers from the World Health Organisation, and the National Institute of Mental Health in the United States, gave their views of the policies of the above organizations in relation to the theme of the conference, and a number of European psychiatrists commented on the importance of the development of psychiatry in primary care settings. Professor J. Cooper commented: 'Our [general] practice system is . . . simple to describe, it is comprehensive, it is universally available and it must be fairly easy to study. Our overseas friends, I think, could be forgiven if they wonder why, when we have all these virtues, we do such a small amount of research into the British system.'

The final session, entitled 'Future Research and Policy', consisted of two papers, one given by Sir Desmond Pond, Chief Scientist at the DHSS, and the other presented by Dr Donald Irvine, the Chairman of the Council of the Royal College of General Practitioners. Sir Desmond highlighted the importance to the Department of research and development in the area of clinical management for patients with mental disorders, and made a 'plea for more involvement of researchers in the development of the results of their findings'. The thrust of Dr Irvine's contribution concerned the 'new realization and acceptance of [his] profession's responsibilities and [their] determination as an important discipline in British medicine to get to grips decisively with [their] outstanding problem of quality control'. Or, as Professor Shepherd remarked in his summing up, so far as future research on mental health in primary care settings is concerned, 'something has to be done to bring in general practitioners on a more active basis. The whole question of how that should be done is, I think, a policy matter.'

The speakers' presentations were followed by lengthy and, at times, vigorous discussions from both the platform and the floor of the hall. A full record of the proceedings will become available in published form in due course.

\section{Acknowledgement}

I am grateful to my colleagues in the General Practice Research Unit who helped in the preparation of this conference report.

\section{British Psychosocial Oncology Group}

A meeting was held in November 1983 at King's College Hospital on the psychosocial aspects of cancer. This meeting attracted a large number of psychiatrists, physicians, social workers, psychologists and nurses who were involved in research and clinical care in the psychosocial aspects of cancer. The conference was extremely successful and it was felt at that time by the participants that it would be useful to establish a British group whose focus of interest would be on the psychological, psychiatric and social aspects of oncology. A committee has now been established for this British Psychosocial Oncology Group under the chairmanship of Dr Stephen Greer at King's College Hospital. It is hoped that this group will be able to organize an annual conference and will be able to produce a newsletter to be sent to the members informing them of recent developments in the field. In the future it may be possible to organize specific training and workshops for interested people. The group also hopes to be able to maintain a register of members with details of their research interests so it can provide a useful central information point for those involved in or embarking upon, research and/or clinical practice in the area of psychosocial oncology.

The group is hoping to attract a wide variety of professional people who are clinically involved in caring for cancer patients and if there are any readers of this journal who would be interested in joining or obtaining further details they should contact the secretary, Dr M. Watson, Faith Courtauld Unit, King's College School of Medicine and Dentistry, The Rayne Institute. 123 Coldharbour Lane, London SE5 9MU.

\section{Psychiatrists Working in Primary Care Settings}

A recent survey indicates that one in five consultants in England and Wales do some work in the Primary Care Setting. It has been suggested that those who spend part of their time in such settings welcome an opportunity of meeting together and comparing styles of practice and other aspects of their work. The Executive Committee of the Section for Social and Community Psychiatry therefore suggested that an informal sub-group could be set up if sufficient members are interested. Dr A. R. K. Mitchell, 40 Top Cliffe Way, Cambridge CB1 4SH, has offered to work as convener of this group and any member who is interested in joining should write to him. 